\title{
The Process Approach to Marketing in the Service Sector
}

\author{
Alina V. Chesnokova \\ Don State Technical University, Shakhty, Russia \\ Oksana I. Radina \\ Don State Technical University, Shakhty, Russia \\ Marina V. Rossinskaya \\ Don State Technical University, Shakhty, Russia \\ Regina I. Serdyuk \\ Don State Technical University, Shakhty, Russia \\ Email: 4335012@gmail.com \\ Natalya V. Klimova \\ Kuban State Agrarian University, Krasnodar, Russia \\ Email: 4335012@gmail.com
}

Doi:10.5901/mjss.2015.v6n3s6p31

\section{Abstract}

One of the problems related to management of competitiveness of the organizations operating in the service sector is poor methodological development of the issues of structure and content of the competitive strategy. The article reviews the most common approaches to understanding of the competitive strategy essence, namely, an approach known as «Porter's competitive strategies», Kotler's approach and the «biological» approach. The assessment of these approaches from the position of their application in the service sector on the example of retailing is provided. The notion of competitive strategy is clarified, and some of the principles of commercial organization competitiveness management, which are to be considered when devising a competitive strategy, are presented. On the basis of the process approach an iterative model of competitive strategy is proposed. The approach depicts the author's vision of the structure and main types of decisions taken when devising, adopting and implementing the competitive strategy.

Keywords: competition, competitive advantages, competitive strategy, organization competitiveness management, principles of competitiveness management.

\section{Introduction}

Quality of service is a major factor in the competition of service industries. Once the service level is lower than expected, the consumer usually very quickly switched to another service provider. Furthermore, it should be noted that currently in marked quality improvement of many industrial products has been increasing attention to quality of service consumers.

The problem of quality control services has long gone beyond the traditional service industries, as illustrated by the desire to manufacturing companies in all possible ways to increase the level of additional services that support their core product.

However, along with the problem of improving the quality of services, one of the most important tasks of the company offering the goods and services, is increasing productivity. Due to the high performance the company is cutting costs, which, in turn, entails a profit increase or decrease in the cost of services offered. In the latter case, the company has all the prerequisites to become a price leader in the market that will result in significant competitive advantage, especially in those segments of the market where consumers are increasingly sensitive to the price factor. Cost reduction makes it possible to invest more in advertising. 
In practice, increase productivity and concomitant increase in activities often have a negative impact on the quality of products and customer service. Therefore, the challenge is to avoid or minimize the potential negative impact on customers and provide the necessary level of service.

Thus, the quality of service and performance are two areas of the value of the product - both for companies and for consumers. Quality of service is focused on the benefits and advantages, which receives the client while the performance is primarily due to the costs, which must be passed on to the consumer.

\section{Methods and Materials}

This quality is very multifaceted and depending on the context can be interpreted in different ways. Thus, F. Crosby primarily by the quality implies conformity to predetermined requirements, while $\mathrm{D}$. Juran emphasis is on meeting the needs of quality.

D. Garvin summarized the existing situation and identified five main points of view on the concept of quality: the transcendental glance; approach based on the product; approach based on user-defined; production approach; approach based on the definition of quality. D. Garvin also managed to identify eight major groups of indicators of quality due to the manufacturing process, which can serve as a basis for analysis and strategic planning (Garvin, 2012):

- The basic operating characteristics;

- Features (this supplement, or so-called "bells and whistles" that accompany the main product, but usually are not included in the standard package);

- Reliability (possibility of breakdowns and failures);

- Compliance (the ability to meet certain specifications);

- Durability (duration to ensure value for consumers);

- Service characteristics (speed and friendly service, efficiency in addressing problems);

- $\quad$ The aesthetic component (impact that product to all five senses of consumers);

- $\quad$ Perceived quality (associative concepts, such as the company's reputation or brand).

However, according to many researchers, the nature of the services is so unique that to define and measure the quality of service necessary to develop and use completely different methods than the manufacturing sector. Due to the intangibility and diversity of types of services the task of assessing their quality seems to be more complicated than assessing the quality of goods. It is necessary to take into account the fact that the consumer is often involved in the service process - especially when it comes to services aimed at the person, so you should distinguish between the concept of the service process (that K. Grenroos called functional quality) and the actual result of the service process (socalled "technical quality").

As practice shows, the most serious study of the quality of services are targeted primarily at consumers. As a result of one such study conducted on the basis of four consumer focus groups, the researchers Zeytaml V., L. Berry and A. Parasuraman were able to identify 10 key criteria that are used by consumers to assess the quality of services (Parasuraman et. al., 2013).

More recent studies have shown that these criteria are significantly correlated with each other, making it possible to combine them into five broader indicators:

1. Tangible characteristics (type of physical elements).

2. Reliability (stability and clarity of operation).

3. The reaction rate (speed and efficiency in solving problems).

4. Confidence (competence, reliability, and security).

5. Empathy (availability, sociability, understanding the needs and concerns of the client).

Following this, to measure customer satisfaction with the different aspects of quality of service A. Parasuraman, V.A. Zeytaml and L. Berry developed a special tool, called SERVQUAL. It is based on the assumption that the consumer evaluates the quality of services by comparing their expectations with the actual perception. The basic version of SERVQUAL model includes 22 factors of perception and expectations, reflecting the five above-mentioned criteria of quality services6.

Despite the fact that the method SERVQUAL today is used intensively by many service companies, researchers do not cease to express doubts about its conceptual framework and methodological limitations.

So, to test the hypothesis of the applicability of the five proposed indicators for assessing the quality of services in Mels, C. and D. Nel Boskhof conducted a study on the basis of several companies from various industries services sphere (Mels, 2014). As a result of studies, it was found that in practice the system SERVQUAL rating reflects only two factors: the internal quality of service (analog functional quality concept proposed by K. Grenroosom) and external quality 
of service that characterizes aspects tangible service process and to some extent reminiscent that $\mathrm{K}$. Grenroos called technical quality (Popkova et. al., 2013).

Based on other studies, during which compared the results of two similar tests conducted over a period of time, the researchers S. Lam and C. Wu hypothesized that at different times on the scale SERVQUAL score may be different. So, if the points mentioned by respondents on items in the group expectations for a long time remained relatively unchanged, the assessment of real perception is largely varied, even if it was about two tests carried out at intervals of just one week.

Meanwhile, the evaluation of the quality of service based on the relationship between consumer expectations and real perception obviously imposes a number of important assumptions. So, if consumer expectations are too low, and the quality of service is significantly higher, one can hardly say that the client has been granted the excellent service.

Studies of quality of service based on customer satisfaction, based on the assumption that the customer has to do with the services with strong empirical and search features. Therefore, as a rule, problems arise when consumers are asked to rate the quality of services, the main characteristic of which is trust (eg, health care). In this case, the consumer is difficult to predict in advance, for a quality of service he can count. Moreover, he may never know how well it served in a company providing complex professional services. In this situation, a natural remedy is that the customer will appreciate the quality, based on the characteristics of the process, for example, determine whether he liked the personal style of a professional, as well as the extent to which he was pleased with the quality of additional services that he is able to appreciate.

J. Delvin and H. Dong suggested basic rules that can be guided in practice to measure the quality of service on any aspect biznesa9. To the consumer it easier to recall the impressions of the service provided, he offered to re-pass all stages of the service process with the mid-term evaluation of each of them (the method of incremental audit). linked.

As noted earlier, the problem of improving the quality of service and performance in service companies are closely

In the industrial sector performance reflects the ratio of products produced and consumed resources. Improved performance can be achieved either by reducing the resources spent on the creation of a certain volume of output, either by increasing the volume of output at the same volume of consumed resources.

It should be noted that due to the prevailing intangible nature of services performance evaluation in the field of service - more difficult than in manufacturing industries. In the case of a service firm performance should be read in conjunction with aspects of the quality and value of services.

One of the tools to prioritize the changes on-fission to increase customer value in the product or service is the "house of quality". Loyal to the company's customers will eventually become for her increasingly profitable, ie. E. A high quality service begins to bring additional revenue.

In this regard, John. Shaw suggested that the main measure of productivity growth in the service sector should be the consumer. At the same time he proposed to use to analyze and compare the performance of the following indicators:

- Profitability per customer;

- The cost of equipment used to service a single customer;

- $\quad$ Equity used to service one customer.

Improving the quality of service and performance together represent a means of increasing product value for both the company and for consumers. The main task for each firm in the service sector is achieving results satisfying its customers in ways that provide the desired cost-effectiveness of the company (Popkova et. al., 2013).

The success of strategies aimed at increasing the value of the product is largely determined by the continuity of measures to improve the quality of service and to increase productivity without coming into conflict with the interests of customers and on the other hand, with an increase in the degree of their satisfaction.

The most common tool for gathering information about the actually-reached-mentioned services as a method of "mystery shopper", involves filling out a questionnaire drawn up by the method of SERVQUAL. Processing profiles can be performed in statistical software packages such as SPSS12.

Thus, the methods of evaluation and analysis of the results should be complemented by methods to improve the quality and design techniques characteristics of the services. Together, these methods are supplemented by institutional arrangements and form a system of services quality management.

\section{Subject}

The subject of the research is in the field of marketing services, as well as the quality of services as a key factor in the competitiveness of service companies. 


\section{Results}

One of the priorities of the Russian economy is to increase competitiveness, which is determined by the competitiveness of the organization, including operating in the service sector. Recognized in theory and practice management issues of competitiveness of commercial organizations are still not only search, study, development, and the prospects for adequate changes in the external and internal environment, rapid adaptation of the competitive strategy of the organization, as well as its implementation. One of the reasons mentioned problems is the weak methodological elaboration of a number of problems in the theory of management of competitiveness, including the question of the essence of competitive strategy.

The purpose of this article is to develop a model of competitive strategy of the organization that operates in the service sector on the basis of the process approach. In this case, a process approach, we understand the approach that considers management not only as a set of interconnected continuous-known management functions but also as a set of continuous interconnected business processes in the context of their results.

To achieve this, we consider it necessary to do the following:

1. Provide more accurate determination of the basic concepts of the theory of management of competitiveness needed to study the modern approaches to the development of competitive strategy, such as "competition", "competitiveness", "competitive advantage", "management of competitiveness."

2. Briefly review the concept of "strategy" and "Competitive Strategy".

3. Present the refinement of the principles of management of competitiveness, relevant for the services sector.

4. Briefly discuss the most well-known approaches to the interpretation of competitive strategy and make their assessment from the perspective of the application in the services sector.

5. We propose a model of competitive strategy.

Research and refinement of the basic definitions of the theory of management positions with competitive marketing approach was carried out earlier by the author. In this article we cite some of the definitions in order to proceed to consider the essence of the concept of "Competitive Strategy", according to which in the literature are the most important differences.

Under the marketing approach to the competition here and will continue to understand the approach based on functional marketing as philosophy and technology business, providing market orientation of the commercial organization, its competitiveness.

It should be noted that the marketing approach is within the behavioral (the activity) approach to the study of competition, which, along with the structural approach is the methodological basis of the study of modern competitive processes. Known supporters of the activity approach to the study of competition among foreign scientists are Schumpeter, Hayek, I. Kirzner, M. Porter, J.-J (Kirzner, 2013). Lamb, among domestic - A.Y. Yudanov, R.A. Fathutdinew, J.B. Rubin, V.P.Gorev and others (Rubin, 2013). Questions evolution of views on competition and forms of competition in the context identified two methodological approaches to the study of competition are well represented in the national literature.

Talking about the competitiveness of the organization, it should be noted that this question is poorly designed in the economic literature. Specialists are usually associated with the competitiveness of the organization competitiveness of its products, while ignoring other aspects of the market-oriented policies. However, practice shows that sometimes superior compared to competitors products remain unclaimed due to the fact that the market policy as a whole does not allow the organization to fully create value, sought its target consumers at the required level. This is especially true for the services sector. In view of the organization's competitiveness, we offer the ability to understand its function in conditions of competition, with the level of profit is not below the average market value in a particular sector of the economy, in a certain area in a certain period of time based on the appropriate from the standpoint of the interests of the target market and their own capabilities, combination of competitive advantages, formed at the expense of all aspects of market policy.

Hereinafter competitive advantage - the superiority of the commercial organization in the field of significant (in terms of ensuring loyalty) combination and level values of the desired target consumers provided average level of costs and / or excellence in costs, provided that the target consumers of the desired values on the average level. In turn, the competitiveness of the commercial organization - an iterative process aimed at the development of coordinated strategic, tactical and operational decisions taken on the basis of an analysis of market opportunities within each iteration, allowing search, formation, adaptation, maintenance and implementation of competitive strategy, to ensure the competitiveness of the organization. An important provision, follows from the definitions is that the object of the organization is the management of competitiveness of its competitive strategy (Popkova et. al., 2013).

P. Smith, K. Barry, A. Pulford believe that "when it is necessary to define a strategy to achieve consensus among 
professionals is very difficult" (Smith et. al., 2014). Theorists, experts and practitioners point of view on this matter quite different. Some see strategy as a retrospective process, others - as a descriptive, while others - like iterative. Even the authors of textbooks have not been able yet to develop a common definition, so to speak of a common approach to the development of good strategies currently is not necessary.

Defining the strategy, G. Mintzberg suggests consider it in five aspects: plan, the principle of position, perspective, welcome (Mintzberg et. al., 2013).

In this article, the study of the different positions on the essence of the strategy will focus only on the two most common positions in the literature, which left their mark on the approaches to the development of competitive strategy. One group of authors believes that the strategy - it is a vector defining the direction of movement, another group of authors insist that this is a detailed map of the area, a detailed plan of action.

In a previous study, it was clarified that the competitive strategy - a system of interrelated with the current and future situation in the market environment and with each other strategic, tactical, operational decisions aimed at a systematic search, formation and maintenance of appropriate combination for the target market and the level of internal and external competitive advantages for the competitiveness of the organization. This provision identifies the need to consider in the management of competitiveness (competitive strategy) a set of principles:

1. The principle of market orientation, at all levels of decisions.

2. The principle focus on specific segments (segment - a set of existing and potential customers, homogeneous in terms of the combination and level of desired values important to select the commercial network and Loyalty).

3. The principle of forming positioning strategy based on a meaningful combination and the desired level of value to the consumer target market.

4. Principle of adequate positioning strategy of choice of market-based policies, the implementation of which will ensure implementation of the strategy as a whole.

5. The principle of economic feasibility of solutions for each element of market-based policies for each program of action in order to find an acceptable compromise between internal and external competitive advantage.

6. The principle of integration solutions at all levels.

7. The principle of conformity available resources decisions taken.

8. The principle of clarity of decision making for all staff involved in their implementation.

By adhering to the principles 1,6,7,8, ceteris paribus implementation of competitive strategy depends, including through its adaptability to changes in the market environment. Implementation of the principle 2 in relation to the services sector retailers will require such a choice as target segments that will develop and implement a consistent strategy of positioning the network as a whole. The implementation of the principle of 3 for trade network operating in multiple formats on multiple segments will require a positioning strategy for each segment and format.

\section{Discussion}

Question of the essence of competitive strategy is presented very contradictory positions of famous scientists. This determines the need for its consideration. In accordance with the approach, known in the literature as "competitive strategies M. Porter," called three possible strategies: cost leadership, leadership in the uniqueness, leadership in focusing on the segment. It is interesting to note that Porter did not call these strategies competitive, and to treat them as generic (positional) strategies that characterize the position in the industry, as understood approach to the development of competitive strategy broader than the definition of position in the industry. Considering the approach to the development of competitive strategy, he proposed to take into account two main points: the structure of the industry, represented in his opinion the five forces that affect the competitive position of the company (direct competitors, potential competitors, substitutes, suppliers and customers), and the position in the industry, which depends the type of competitive advantages (low cost, differentiation, focus on the segment). At the same time, M. Porter believed that each of these moments in itself is not sufficient to select competitive strategy. Thus, the firm in a very lucrative industry cannot get a big profit if properly selects the position in the industry.

One of the reasons that his positional strategies are known as competitive, in our opinion, is that each of them is based on one of three possible types of prevailing competitive advantage: cost leadership, leadership in product differentiation, lead in focusing on the segment. Fig. 1 shows the well-known retail formats in the coordinate system of the matrix M. Porter positional strategies developed by them, where in fact not allocated 3 and 4 possible positional strategy (Porter, 2013). Consideration of approach to the development of competitive strategy, allocate 3 of the "competitive strategies", leads to the following conclusions: the approach treats strategy only as a vector defining the direction of the 
goal, and not possible to get an idea of the necessary steps for the implementation and transformation of such a competitive strategy; greatly simplifies the vision of competitive strategy from the perspective of M. Porter; does not allow us to answer the question of how to compete with each other, for example, supermarkets, discounters, while competition between them within a sales area is very strong and they need to be efficient and flexible competitive strategy.

Moreover, arguing in his early works, which they identified between basic types of competitive advantage is built-in contradiction to the later works of $\mathrm{M}$. Porter largely adhered to the concept of acceptable compromise between them and thus compromise between the activities of the company, by which competitive strategy can be implemented. Thus M. Porter sees competitive strategy rather than as the direction of movement toward the goal, and as an interrelated set of strategic, tactical and operational decisions and actions, including trade-offs (Porter, 2012). For services retail trade-offs can be made during the development of retail formats. Currently, the border between the known formats are blurred. It is difficult to clearly define what a supermarket, discount stores, although for the latter there are certain characteristics of economically viable size of retail space, the number of its sales range, location, merchandise, attitudes towards advertising and a number of others. An example of a blur formats and complex trade-offs in terms of action by which the competitive strategy is implemented, can serve as a well-known and highly successful network of discounters.

Another well-known approach to the description of the competitive strategies of modern Russian literature, including training, was the approach outlined by Kotler (Kotler, 2013). In his works he considers a strategy rather as a vector, rather than a detailed plan of action, and calls his proposed strategy for marketing, reflecting the best traditions of modern marketing philosophy. However, since all of them are directly related to the competitive position of companies (leaders, contenders for the leadership, followers, and the inhabitants of market niches) and due to its competitive strategy, in many domestic sources of literature they are treated as a competitive strategy. Kotler says marketing (competitive) strategies in the context of our growth strategy by expanding its share of the market or, planned reductions, hold positions, and so on. N. In this case, it offers a focus on the only indicator of "market share". In accordance with this approach, companies depending on market share should choose the recommended Kotler marketing (competitive) strategy and based on the actions and targets for each type of strategies to judge what purpose can be basically rational and what is not.

Among the limitations of using the proposed approach in the services sector, in particular retail trade services, include the following:

1. A simplified approach to the definition of the company's position as the only indicator is considered "market share". In this case, the context indicates that the company, having the highest share of the market, has great resources and can afford these methods of retention and expansion, which cannot afford to competitors. However, the practice of companies the past 40 years has shown that the presence of a high market share does not mean the adequacy of the resources needed to implement the actions in the fight against competitors that are contained in the works of $F$. Kotler. This is due to the presence of a non-profit areas. Studies conducted Slivotski A. and D. Morrison revealed that many well-known companies with high market share, had little or no income and had handed over their competitive position in the specified time period (Slivotski and Morrison, 2012). With regard to trade significant in this regard known antagonism American retailers Kmart and Wal-Mart. In addition, research scientists in the domain of the company's market position argue that it depends not only on market share, but also on factors such as its elected positional strategy by M. Porter, or its chosen strategic model (selling bulk commodities with low mark-up and a high rate of turnover or sale of specialized products with high margin and low rate of turnover), as well as what the company has the loyalty of their target consumers or not, what are the trends in this loyalty.

2. The need for very serious additional developments in the establishment of the type of decisions, the nature of their relationship with each other and the environment, identifying a set of actions required to implement the chosen competitive strategy, and most importantly - method of determining when it needed to adapt to changes.

3. Inability to get an idea of competitive strategy, even as a vector, which determines the course of action for the service industries, the main focus of behavior which Kotler said various kinds of specialization. For example, the market of retail services for specific outlets are always local, tied to a particular sales area. All of them are in some way the inhabitants of niches, because even retail chains adapted positioning and market policies, many decisions under the specific features of the trade area. However, the strategic model, which they hold, can be fundamentally different: the high turnover rate - low margin / low turnover rate - high margin. Obviously, one can speak of specialization only in the latter case. Development Kotler, judging by the examples cited by him, may be to some extent useful for enterprises producers of mass production, which bind to specific sales area does not have such importance, both for service businesses, such as retail services. 
Another approach to understand the essence of competitive strategy is the so-called "biological" approach, in which, by analogy with the strategic behavior of the species $\mathrm{H}$. Winkel Frize- were identified types of competitive behavior of firms.

This approach identified the name of competitive strategies or behavior of firms: violentnoe patientnoe, ruderal. In the future, biological approach has been developed in the works of Yudanova, who introduced another type of competitive behavior (Yudanov, 2013). As a result, a special Russian literature with a non-significant discrepancies described four types of competitive strategies: violentnaya (power) competitive strategy, suitable for large companies operating in the field of mass production; patientnaya (tolerant, hardy) competitive strategy, which consists in adapting to the segments (niches), on the basis of specialization; ruderal (Pioneer) competitive strategy, consisting in the orientation of new products and capture them on the basis of the market; kommutantnaya (adaptable) competitive strategy that focus on adaptation to the demands of the local market and capture niches not occupied Violentyev and patient's samples. A more detailed description of the history of the formation and nature of "biological approach" is given in the article by A. Trachuk (Trachuk, 2013). Recognizing that the approach considered reasonable schematically describes patterns of behavior in a competitive environment, depending on the type of competitor, it should be noted that it is the same as the approach Kotler, to a small extent consistent with the principles of management of competitiveness, and therefore cannot develop, adapt and implement competitive strategy for enterprises and organizations operating in the service sector.

Based on the research of numerous approaches and principles of management of competitiveness of the commercial organization, as well as clarify the definition of "Competitive Strategy" was formulated by us and provided a process approach to the representation of the structure of competitive strategy. We have previously developed a model of management of competitiveness of the commercial organization. Given that the object of such management is a competitive strategy, this model, after some improvements based on the results of the analysis of approaches to competitive strategy may reflect the structure of the competitive strategy of being fixed at a planning period, the amount of which is determined in each case individually, taking into account competitive conditions functioning of the organization.

The double arrow in the model indicates a relationship with the market environment of all decisions and actions, and double-sided arrows 1, 2, and 3 reflect the iterative nature of decision-making at each level and the overall model. These links provide adaptability of the current competitive strategy, the ability to quickly respond to market changes, which allows us to process approach to competitive strategy. In this adaptation of the current regime in the first place may be subject to decisions on programs of action to implement market-oriented policies and in some way part of the market and the very policy. Thus, the proposed approach provides a learning opportunity.

\section{Conclusion}

In conclusion, it should be noted that the merits of the proposed model of competitive strategy is the fact that:

- The model is directly related to the process of management of the organization, its structure consists of three levels of the decisions necessary to generate, adapt and implement competitive strategies;

- In the model identified the main types of issues on which it is necessary to make decisions, and the relationship between the solutions of different levels. The nature of the relationship indicates that the iterative nature of the model, every decision a higher level compared with the possibility of its implementation from the perspective of opportunities as the organization itself, and from the standpoint of current / prospective situation in the market environment;

- Model not only serves the goals of the organization, but also allows you to transform these goals depending on the specific market opportunities, including development.

Consequently, the focus on refined definition of "Competitive Strategy", presented in the article the basic principles of management of competitiveness of the commercial organization, as well as a model of competitive strategy, developed on the basis of an analysis of existing approaches to competitive strategy, to construct and implement adaptive competitive strategy for organizations operating in the service sector. The proposed model of competitive strategy is based on the process approach to management competitiveness organization operating in the service sector.

\section{References}

Garvin, D. (2012). Managing Quality. New York, pp. 112.

Gorev, V. P. (2014). Russian economy in international competitive relations. Irkutsk, Baikal State University of Economics and Law Publ., pp. 161. 
Kirzner, I. M. (2013). Competiton and Entrepreneurship. University of Chicago Press, 1973. 256 p. Moscow, Yuniti-Dana Publ., pp. 239.

Kotler, F. (2013). Marketing. Management. Analysis, planning, implementation, monitoring. Saint Peretsburg, Piter Publ., pp. 887.

Mels, G., Boshoff, C., Nel, D. (2014). The Dimensions of Service Quality: The Original European Perspective Revisited. Service Industries Journal. 1(1): 173-189.

Mintzberg, H., Ahlstrand, B., Lampel, J. (2013). Strategy Safari: A Guided Tour Through The Wilds of Strategic Management. The Free Press, 1998. 406 p. (Russ. ed.: Mintsberg G., Alstrend B., Lempel Dzh. Management. Saint Peretsburg, Piter Publ., pp. 356.

Parasuraman, A., Zeithaml, V., Berry L. (2013). A Multiple Item Scale for Measuring Consumer Perceptions of Service Quality. Journal of Retailing, pp.12-40.

Popkova, E.G. and Tinyakova, V.I. (2013). New Quality of Economic Growth at the Present Stage of Development of the World Economy. World Applied Sciences Journal, 5: 617-622.

Popkova, E.G., and Tinyakova V.I. (2013). Drivers and Contradictions of Formation of New Quality of Economic Growth. Middle-East Journal of Scientific Research, 11: 1635-1640.

Popkova, E.G., Morkovina, S.S. Patsyuk, E.V. Panyavina E.A. and Popov, E.V. (2013). Marketing Strategy of Overcoming of Lag in Development of Economic Systems. World Applied Sciences Journal, 5: 591-595.

Porter, M. E. (2013). Competitive Advantage of Nations. New York, Free Press, 1990. 855 p. (Moscow, International Relations Publ., pp. 896.

Porter, M. E. (2012). On Competition. Updated \& Expanded Edition. Harvard Business Review Press, pp. 576.

Rubin, Y. B. (2013). Disputable issues of the modern theory of competition. Modern Competition, 3(21): 38-65.

Slivotski, A., Morrison, D. (2012). Marketing at the speed of thought. Moscow, EKSMO Publ., pp. 448.

Smith, P., Berry, C., Pulfoid, A. (2014). Strategic marketing communications: new ways to build and integrate communications. London, Kogan Page Publishers, pp. 320.

Trachuk, A. (2013). The Company Innovation Strategy. Problems of theory and practice of management, 9(1): 15-18.

Yudanov, A. Y. (2013). Competition: Theory and Practice. Moscow, Akalis Publ., pp. 272. 